\title{
Seismic Vibration Control on Reinforced Concrete Structure with Multiple Tuned Mass Damper Considering SSI Effects
}

\author{
Authors Zhirong Xiao ${ }^{1 *} \quad$ Biruk Dollebo $^{2}$ \\ School of Architecture and civil engineering, Zhejiang University of science and technology, \\ Hangzhou, China
}

\begin{abstract}
An earthquake causes a great deal of damage to the structure, that's why many researchers work on the vibration of the structures caused by the earthquake. A fifteen-story reinforced concrete structure with MTMD (multiple tuned mass dampers) is modeled with a fixed and flexible base in SAP 2000. And also deals with the analysis of the structure and the comparison of the Natural periods, Storey displacement, and Base shear of building values under the dynamic condition considering SSI effects. The paper concluded that the natural periods increase when the soil-structure interaction effect is considered as compared to the assumption of fixed support and the story displacements increase when the soil-structure interaction effect is considered as compared to the assumption of fixed support. The analysis of this structure yielded better results under the conditions used by the multi-tuned mass damper.
\end{abstract}

Keywords: Reinforced concrete structures, Earthquake, Multiple Tuned mass dampers, Soil-Structure Interaction (SSI), SAP2000.

DOI: $10.7176 / \mathrm{CER} / 13-2-05$

Publication date: April $30^{\text {th }} 2021$

\section{Introduction}

The behavior of a structure is affected by interactions between the superstructure, the foundation system, and the subsoil. Soil-structure interaction analyses the relations of these systems with each other. Soil behavior is the most complicated subject in these relations. The reliability of structural design depends on how the soil-structure interaction is modeled accurately and realistically. Soil-Structure Interaction (SSI) has long been considered by civil and structural engineers as one of the important issues that may affect the actual behavior and design of the structures (Wolf 1985, Kramer 1996). Observations made during large earthquakes have specifically emphasized the importance of the dynamic soil-structure interaction. The main complexities arise from the inherent complexities in dynamic problems, considerable uncertainties in soil properties as well as seismic input motion, and the extent of parameters affecting the interaction problem, partly concerned with suitable modeling of the soil and its boundaries.

The tuned control devices such as the tuned mass damper (TMD) have been extensively studied and widely applied because the construction and the mechanism of the tuned damper are simple and definite. The most commonly used and most effective tuned damper is the tuned mass damper, which is a vibration system composed of springs or slings, mass blocks, and damper, and it can be installed in a specific location on the structure. Since its natural frequency is similar to one of the main structures, the TMD system can reduce the vibration amplitude of the main structure using generating resonance with the controlled modes of the main structure when the structure is subjected to an earthquake. The tuned mass dampers have been applied in civil engineering such as high-rise buildings, tower structures, and long-span bridges.

Rahul Sawant et. Al. (2016), studied the interaction between the superstructure and sub-structure, it is investigated by modeling the soil as simple as possible to capture the overall response of the system. The nonlinear response of a single-degree-of-freedom system which can be representative of a broad range of newly designed structures is investigated while allowing for flexibility of the soil-foundation system and SSI effects. The nonlinear frame model is a high-rise residential building of $\mathrm{G}+42$ stories located in Mumbai and the time history of EL CENTRO is used to study the response of the model in ETABS. The simple soil model with a pile-raft foundation is then employed in MIDAS GTX NX to this nonlinear frame model to quantify the effect of SSI on the overall response of actual structures. It concluded that the designer should first decide that whether the SSI effect should be included in the design or not by checking the overall site condition, soil properties, etc. The wave nature of SSI effects requires special attention when FEM is used.

Kanhaiya Abhay Zanwar et. Al. (2016), explained that the flexibility of soil causes lengthening of the natural period due to an overall decrease in stiffness of the structural system. Such lengthening alters the seismic response of the building frame to some extent. It is, therefore, necessary that the dynamic inter-relationship between soil and structure be taken into account in the seismic analysis of structures. The structural system is modeled using ETABS V.13 software. The effectiveness and robustness of a particular version of MTMD, called "the multiple dual tuned mass dampers", is analyzed in the paper (Han, Li 2006). The problem of determination of optimum properties of MTMD is considered in the papers ( $\mathrm{Li}, \mathrm{Qu} 2006$; Li 2002). Spatial structures with MTMD are 
analyzed in (Guo, Chen 2007).

Moreover, the possibilities of using the so-called active and semi-active versions of TMD are also considered in some papers (Han, Li 2006; Li, Han 2007; Li, Zhu 2007; Lin et al. 2005).

As mentioned above, different researchers have developed their analysis in different conditions using different software. What makes this study different from the above is that it combines both a combination of soilstructure interaction effect and multiple tuned mass dampers with different conditions likes, fixed base, and flexible base with and without multiple tuned mass dampers in different soil types. Load combinations are taken from ACI $318-05 / \mathrm{IBC} 2003$ code. For this reason, in the present paper, the possibility to reduce the vibration of a frame structure with the help of MTMD is analyzed. The presented description of the structure with MTMD exploits a particular form of the motion equations to simplify the numerical algorithm of the applied method of solution. The structure is under the effect of dynamic forces caused by the earthquake. A multiple tuned mass damper (MTMD) is placed on the top floor of the building and response spectrum analysis has been performed and we found that using MTMD reduced the vibration of the structure in all cases.

\section{Structure models}

\subsection{Structural Modeling with and without MTMD}

Asymmetrical moment resistance frame (MRF) three-dimensional reinforced concrete structure is proposed to be analyzed using SAP2000 with Multiple Tuned Mass Damper (MTMD) and without any damping device. The performance of the building will be studied considering buildings with and without multiple tuned mass dampers. The structural configuration of the regular building is shown and the entire building frame considered is $30 \mathrm{~m} \mathrm{x}$ $30 \mathrm{~m}$ in the plan area. Height of the 1st to 15 th floor of the building has same floor height $3 \mathrm{~m}$ basement floor has $3.2 \mathrm{~m}$. The parameters of the building are shown in table1.

Asymmetrical moment resistance frame (MRF) three-dimensional reinforced concrete structure is proposed to be analyzed using SAP2000 with Multiple Tuned Mass Damper (MTMD) and without any damping device. The performance of the building will be studied considering buildings with and without multiple tuned mass dampers. The structural configuration of the regular building is shown and the entire building frame considered is $30 \mathrm{~m} \mathrm{x} 30 \mathrm{~m}$ in the plan area. Height of the 1 st to 15 th floor of the building has same floor height $3 \mathrm{~m}$ basement floor has $3.2 \mathrm{~m}$. The parameters of the building are shown in table 1 .

A. Assumption

1. Column cross-section gets smaller from the first floor to the top.

2. All restrains that have been modeled are assumed to be fixed.

Table 1 Range of parameters considered in the present study

\begin{tabular}{|l|l|}
\hline Structure type & Ordinary moment resisting frame \\
\hline No. of storey & 15 \\
\hline Typical storey height & $3 \mathrm{~m}$ \\
\hline Type of building use & Mixed used building \\
\hline Material Properties & M25,M30 \\
\hline Grade of concrete & $25 \mathrm{KN} / \mathrm{M}^{3}$ \\
\hline Density of reinforced concrete & $2 \times 10^{6} \mathrm{KN} / \mathrm{m}^{2}$ \\
\hline Young modulus of concrete, Ec & 0.2 \\
\hline Poisson's Ratio of reinforced concrete & 415 \\
\hline Grade of steel & $77 \mathrm{KN} / \mathrm{M}^{3}$ \\
\hline Density of steel & $2 \mathrm{x} 10^{9} \mathrm{KN} / \mathrm{m}^{2}$ \\
\hline Young modulus of concrete, Es & 0.3 \\
\hline Poisson's Ratio of steel & $0.15 \mathrm{~m}$ \\
\hline Thickness of slab & $0.25 \mathrm{~m}$ \\
\hline Thickness of shear wall & $0.2 \mathrm{~m}$ \\
\hline Thickness of external wall & $0.15 \mathrm{~m}$ \\
\hline Thickness of internal wall & $\mathrm{C} 1-0.7 \times 0.7 \mathrm{~m}$ \\
\hline Beam and column cross sections & $\mathrm{C} 2-0.6 \mathrm{x} 0.6$ \\
\hline B1- $0.4 \mathrm{x} 0.7 \mathrm{~m}$ & $\mathrm{C} 3-0.5 \times 0.5 \mathrm{~m}$ \\
\hline B2- $0.4 \mathrm{x} 0.5 \mathrm{~m}$ & $3 \mathrm{KN} / \mathrm{m}^{2}$ \\
\hline B3- $0.4 \mathrm{x} 0.4 \mathrm{~m}$ & \multicolumn{2}{|l|}{} \\
\hline Live load &
\end{tabular}


Table 2 Geometrical parameters of the tuned mass damper

\begin{tabular}{|l|l|}
\hline Mass ratio & $5 \%$ \\
\hline Mass of TMD & $70 \mathrm{KN}$ \\
\hline Stiffness of damper & $640 \mathrm{~N} / \mathrm{m}$ \\
\hline Damping ratio & $0.1,0.2$ and 0.3
\end{tabular}

Before using MTMD, we adjust the layout of our building by adding center-to-center distance. Then enter the material properties data of concrete and rebar. We include the material type of concrete and rebar, unit weight, modulus of elasticity, Poisson's ratio, specified concrete compressive strength as well as minimum yield stress, minimum tensile stress, expected yield stress, and expected tensile stress of the rebar. Select the material properties listed above and enter the section properties (depth and width) of a beam, column, slab, and shear wall to model the building structure. After modeling, we used MTMD to reduce the lateral displacement of the structure. MTMD has its mass, stiffness, damping coefficient, Damping ratio, and damping exponent, so we enter the values we selected for this project. Within SAP2000 MTMD modeled using a Spring-Mass system with damping guidelines for this subsystem is described below. To apply MTMD on the main structure, first select the properties link or support type of damper, and then select the spring properties to draw a linear two-joint link object in which one joint is attached to the structure and the other joint is free. Mass and weight of dampers are then assigned to the free joint. After modeling using the above parameters, select the computer and structures $\backslash$ sap $2000 \backslash$ time history file, El-Centro, then enter the load case type (nonlinear modal time history using dependent Ritz vectors, dead, live, and earthquake load case).

\subsection{Structural modeling with and without MTMD considering SSI}

After modeling the structure with or without MTMD according to the above section, in this section, we modeled another new building structure with a flexible base using different soil parameters. To model it, we must select the material and section properties of soil. Material properties of the soil are weighted per unit volume, Isotropic property data (Modulus of elasticity, Poisson's ratio, Coefficient of thermal expansion and Shear modulus) and soil types (soft and hard), friction angle of the soil, section solid properties of the soil and damping properties the soil. The soil is modeled with four-node quadratic elements forming a $(30 \mathrm{~m} \times 30 \mathrm{~m}$ and the total height of the building is $45 \mathrm{~m}$ from the original ground level. The boundary is extended $6 \mathrm{~m}$ and $8 \mathrm{~m}$ from the original structural surface area in both (X and $\mathrm{Y}$ ) direction and the soil is assumed to be a single layer of 10meter deep and had been done with different boundaries are extended and the results are evaluated from software analysis. The material chosen to represent the soil quad elements is the "Pressure Depend on Multi Yield" material that defines the nonlinear behavior of soft and hard soil. The geometric parameter of the soil is described in detail below in table 3. And also considering different boundary conditions with different geometrical parameters of soil type and considers conventional finite element capabilities and investigates the effects of some important analytical modeling parameters on the dynamic response of structures under concurrent horizontal and vertical ground motions and compare which one is suitable for our project. Among various parameters affecting the soil-structure interaction, it focuses on the effects of the structural type and aspect ratio, the soil mass, dimension of soil model, and boundary conditions. The results of software analysis of various boundary conditions are described below. The damping is assumed as 5\% of the critical damping using the Rayleigh damping definition. The construction of the soil-structure model is completed using nonlinear GAP connector elements between the reinforced concrete foundation of the structure and the soil. The nonlinear GAP elements consist of an elastic spring and an incorporated opening so that no tensile forces are transmitted between the structure and the soil. For the model used in this research zero initial openings have been assumed. The stiffness of the spring is calculated so that the compressive forces are transmitted with negligible relative displacements between the foundation of the structure and the soil. For this purpose, the GAP elements are defined every one meter along the length of the structural foundation with a sufficiently high spring stiffness value $\left(10^{4} \mathrm{KN} / \mathrm{m}\right)$.

Table 3 Geometrical parameters of soil

\begin{tabular}{|c|c|c|c|c|c|}
\hline No & Soil Type & Density of Soil ( $(\rho) \mathrm{KN} / \mathrm{m}^{3}$ & Modulus of & Elasticity (E) MPa & Poisson's Ratio $(\mu)$ \\
\hline 1 & Soft soil & 16 & & 15000 & 0.4 \\
\hline 2 & Hard soil & 18 & & 65000 & 0.3 \\
\hline
\end{tabular}

Table 4 Boundary condition of the soil

\begin{tabular}{|l|l|l|}
\hline Soil types & \multicolumn{2}{|c|}{ Boundary conditions } \\
\hline Soft soil & $6 \mathrm{~m}$ & $8 \mathrm{~m}$ \\
\hline Hard soil & $6 \mathrm{~m}$ & $8 \mathrm{~m}$ \\
\hline
\end{tabular}

\section{Analysis of models}

The building was first analyzed with the fixed base condition and flexible base resting on elastic continuum soil 
boundary with two different soil types namely soft, and hard. The analytical calculation was also carried out to find the base reaction of RC frame building with the fixed base condition the structural analysis modal periods, story displacements, and base shear of the building. All the above-stated parameters are compared in joints in the $\mathrm{X}$ direction for 607 joint; the joint taken for comparison are peripheral edge joint. Modal analysis is carried out to obtain the mode shapes and fundamental period of the structure. Thus the results obtained after the analysis are as follows:

\section{A Natural period}

Natural periods obtained from the analysis for a flexible base with different soil and fixed base without MTMD are shown below.

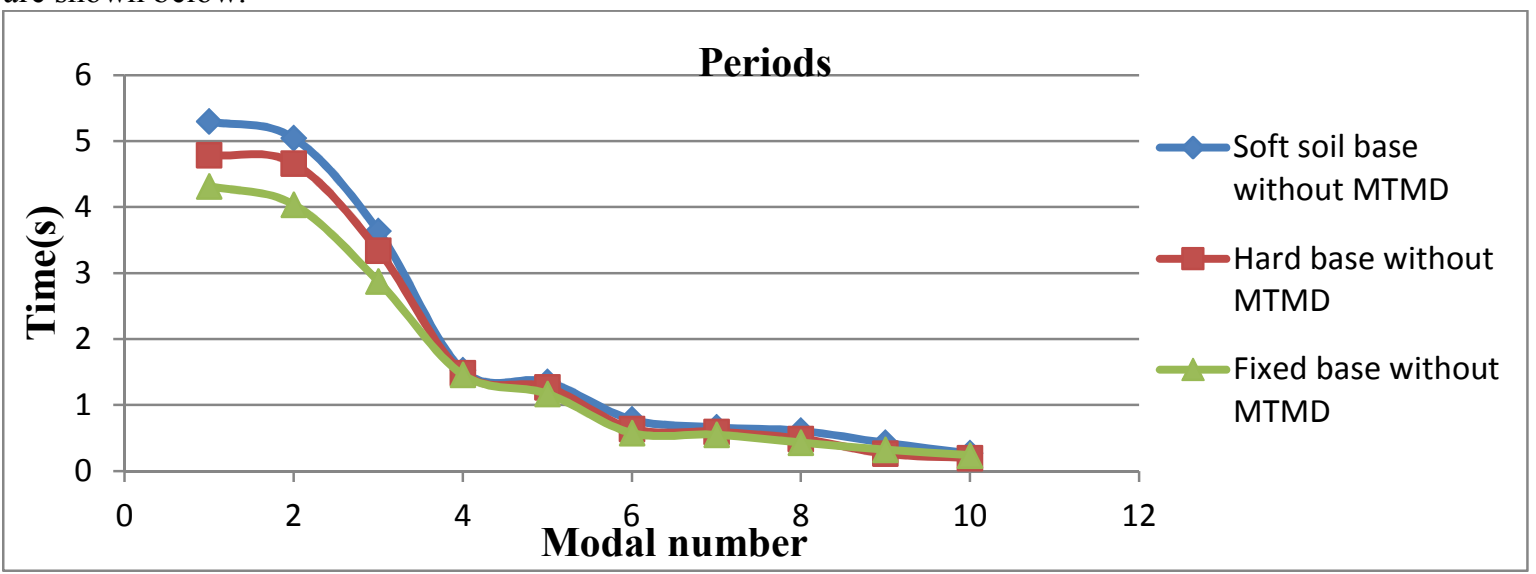

Figure 1 Comparison of natural period's with different soil types and fixed base without MTMD

We obtained different results by expanding the area of the building using $4 \mathrm{~m}, 6 \mathrm{~m}$, and $8 \mathrm{~m}$ soil size with different soil types such as soft and hard soils in the X and Y directions. The results obtained using $4 \mathrm{~m}$ and $6 \mathrm{~m}$ soil sizes are very similar and are not suitable for this study. As a result, we selected $8 \mathrm{~m}$ soil size with different soil for this study. Accordingly, we compare the results obtained in figure-1 with a fixed base and in different soil types with $8 \mathrm{~m}$ soil size. As we can see from the above graph, we obtained different natural periods in all cases. A flexible base has larger natural periods than a fixed base. Because a fixed base has high stiffness than a flexible base. If there is a large stiffness, there will be a small natural period. Hard soil is also stiffer than soft soil and it has small natural periods than soft soil.

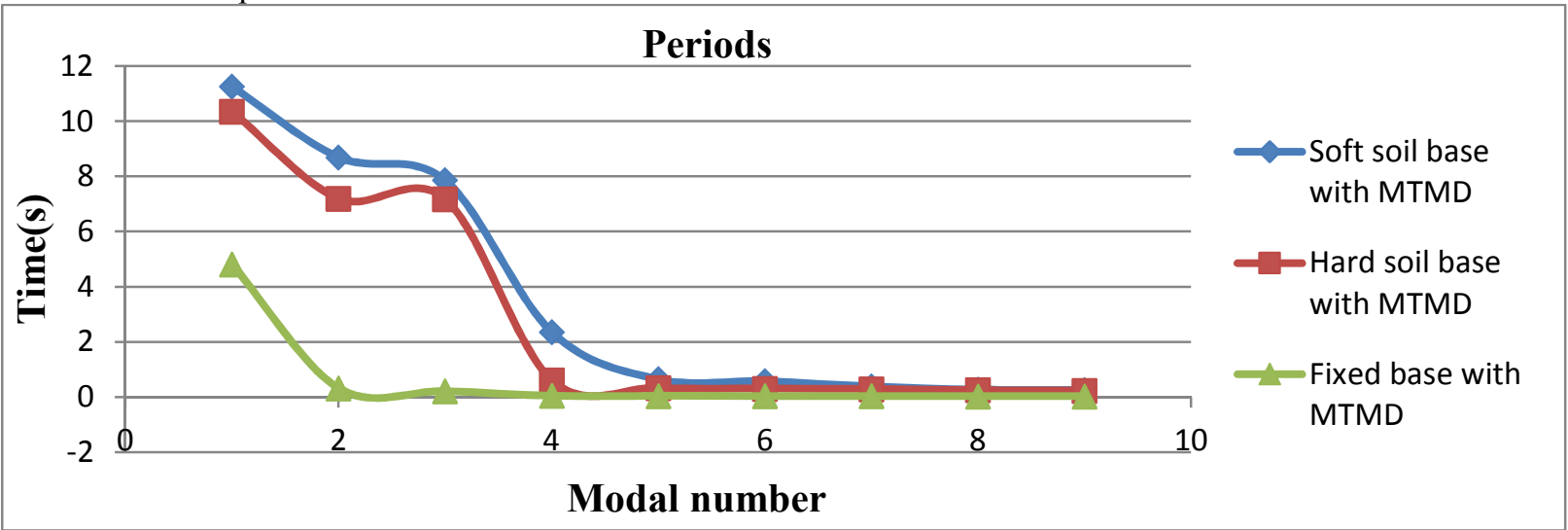

Figure 2 Comparison of natural period's with different soil types and fixed base with MTMD

As we can see from the above figure-2 the natural periods of the reinforced concrete structure are different in all cases. The fixed base with MTMD is stiffer than the flexible base that's why the flexible base has high periods than the fixed base. Fixed base with MTMD has small periods than hard soil and soft soil with MTMD because it's stiff than others and also hard soil with MTMD stiffer than soft soil with MTMD and it has small natural periods than soft soil. Natural periods of buildings reduce with an increase in stiffness.

B Story displacements

During an earthquake, the building vibrates. We use MTMD to control the vibrations during this time. We also need to consider the soil effects below the superstructure. Story displacement is one of the parts that explain the benefits of MTMD during the earthquake and the soil effects below the supper structure. In this section, we have analyzed the results of all cases. 


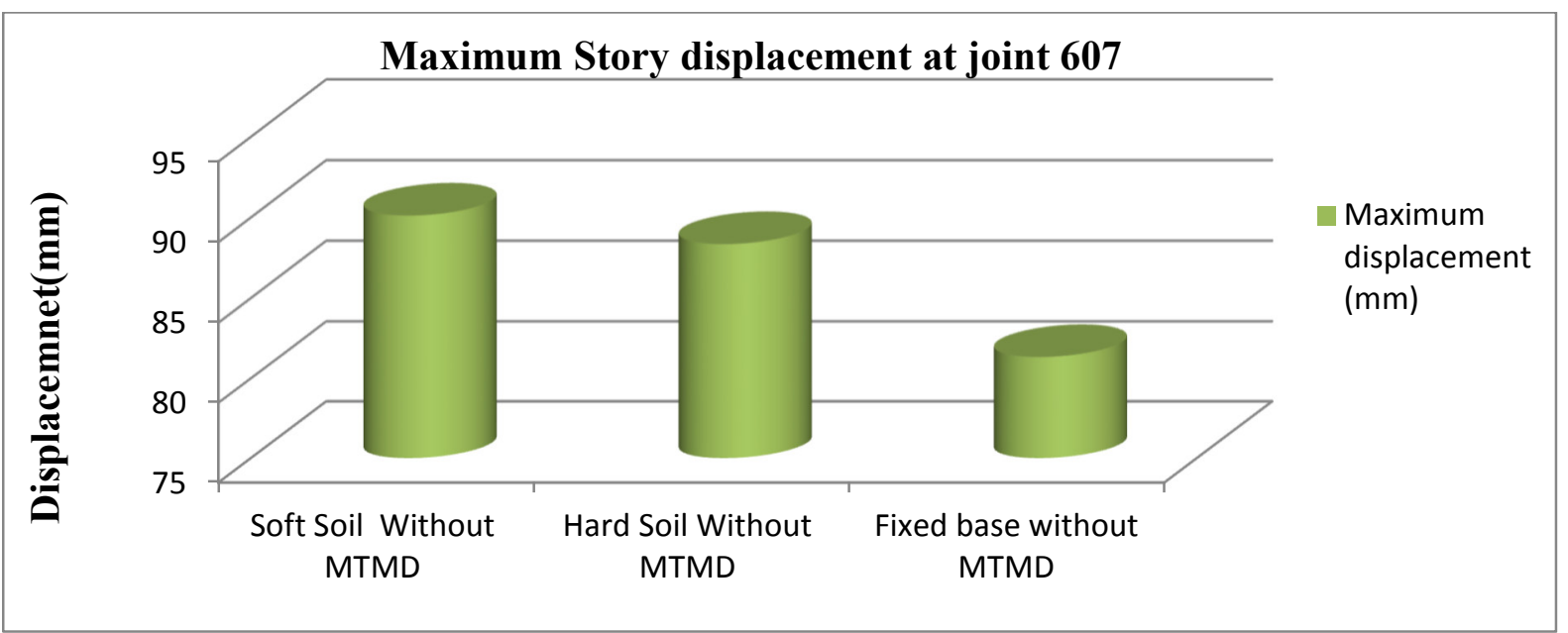

Figure 3 Maximum story displacements at joint 607 without MTMD

The results of the analysis in figure-3 show that under the EL-Centro earthquake soft soil is $4.42 \%$ more displaced than hard soil with the same boundary condition and hard soil is $7.93 \%$ and soft soil is $9.24 \%$ more displaced than fixed base without MTMD.

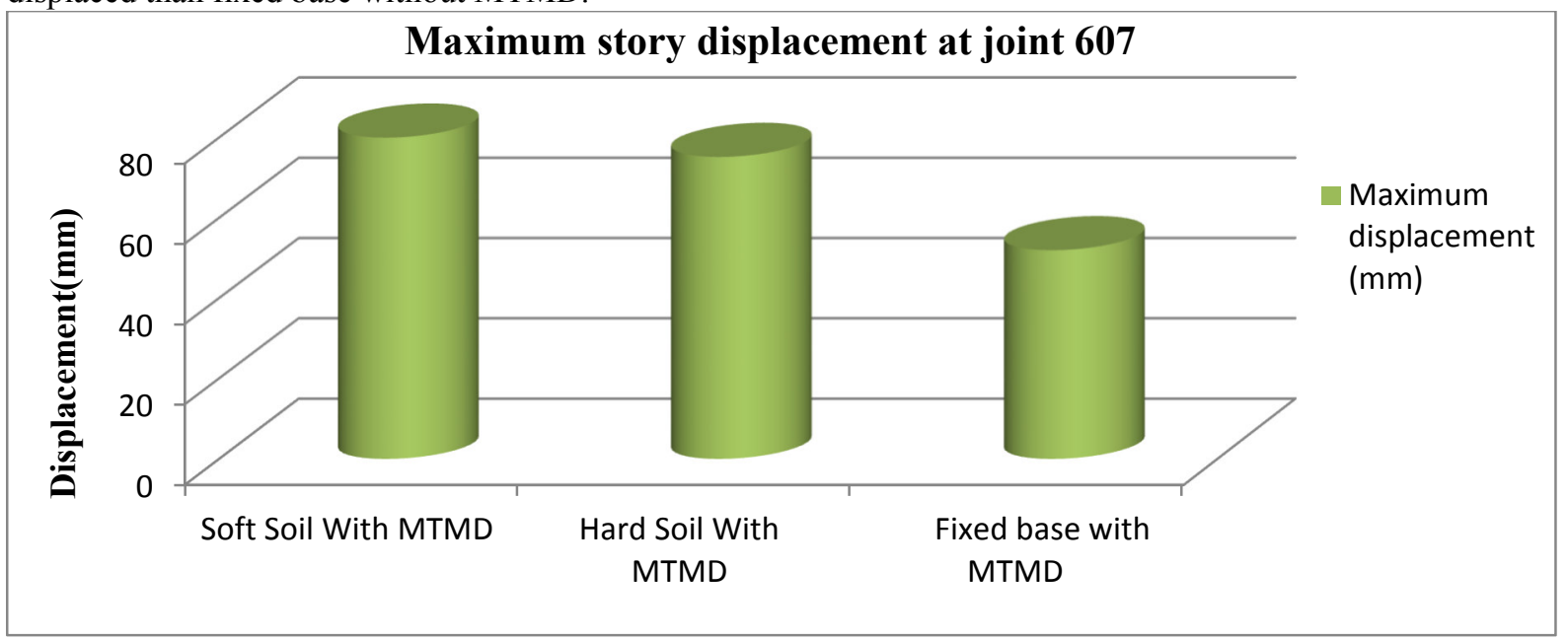

Figure 4 Maximum story displacements at joint 607 with MTMD

According to the above graph, under the EL-Centro earthquake, soft soil without MTMD is $11.27 \%$ more displaced than soft soil with MTMD. There is a difference between hard soil with and without MTMD. That is, hard soil without MTMD is $14.93 \%$ more displaced than hard soil with MTMD and also there is a difference between the fixed base with and without MTMD. Fixed base without MTMD 36.1\% more displaced than a fixed base with MTMD and hard with MTMD displaced 30.92\% more than a fixed base with MTMD. Overall, the analysis of this structure yielded better results under the conditions used by the multi-tuned mass damper. That means MTMD has successfully reduced the lateral displacement of the structure.

\section{Base shear}

According to the software analysis base shear of the proposed building with a fixed base and flexible base with and without MTMD, all the results are described below. The base shear of the structure can be also affected by the ground motions concerning different soil types and the stiffness and displacements of the structure during the earthquake. The results in the graph below are obtained from a fixed base with and without MTMD and hard soil with and without MTMD. 


\section{Maximum base shear (KN)}

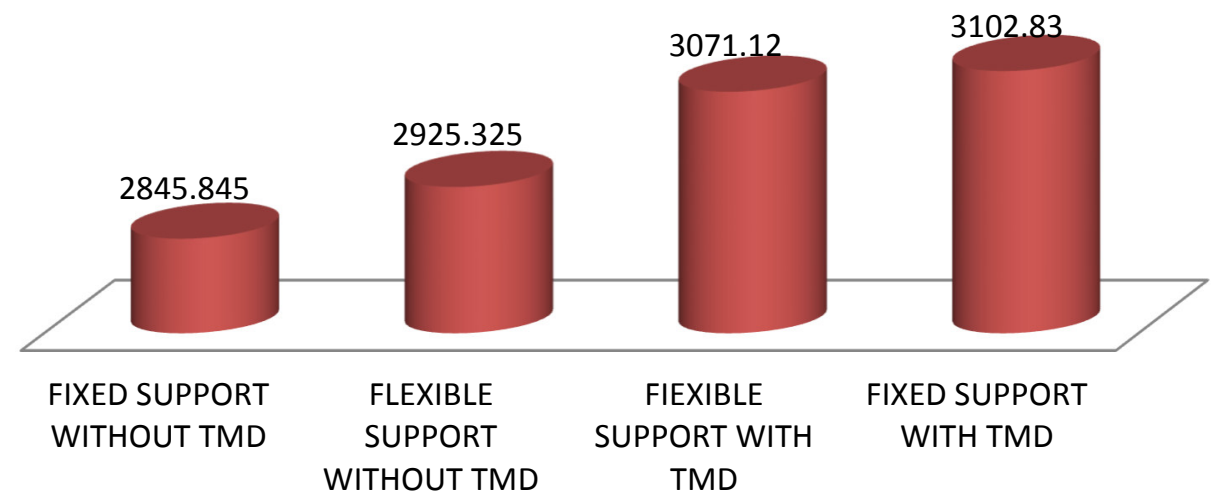

Figure 5 Comparison of Base Shear in X direction with and without MTMD

Under the El -Centro earthquake, different base shear results are shown in all cases. There is some difference between the fixed base with and without MTMD, the base shear of a fixed base with MTMD is 7.33\% higher because it has higher stiffness and the story displacements are smaller than the fixed base without MTMD. And also there is a $5.7 \%$ difference between the flexible base with and without MTMD, base shear of a flexible base with MTMD has higher than flexible base without MTMD, but there is no wide difference between the two cases: fixed base and flexible base with MTMD because both are relatively they have high stiffness and low story displacement, but there is a small (1.022\%) difference between them, base shear of the fixed base with MTMD has a higher value. Overall, the MTMD and SSI effects are visible in this section. Fixed base structure with MTMD has high stiffness $(\mathrm{K})$ then it will also displace less (low $\mathrm{U}$ ) and flexible base structure has low stiffness (K), it will displace much more (high $U$ ) resulting in more or less the same amount of base shear $=\mathrm{K} x \mathrm{U}$. Therefore, the building with more seismic weight will be having high base shear and low natural period.

\section{Summary and Conclusions}

Multiple tuned mass dampers are one of the advanced vibration control systems. Using different parameters, we molded our building into a fixed and flexible base with different soil types and soil sizes in sap2000. We also used MTMD after modeling the main structure. After modeling, we performed a fixed and flexible base with and without MTMD, and we obtained different results by comparing natural periods, story displacement, and base shear under different conditions. Generally, natural periods increase when the soil-structure interaction effect is considered as compared to the assumption of fixed support in both cases with and without MTMD. We can observe that the story displacements are high when soil-structure interaction is considered. Applying the damper to the structure we observe that the displacement of the structure is reduced. Finally, in the above sections under the El -Centro earthquake in all conditions i.e. $8 \mathrm{~m}$ boundary conditions with soft and hard soil types and analysis of building structure with and without MTMD considering soil-structure interaction effects between the superstructure and the soil, we found important points in detail they are listed below.

- Natural periods increase when the soil-structure interaction effect is considered as compared to a fixed support. - Fixed base with MTMD is stiffer than the flexible base that's why the flexible base has high periods than the fixed base. Natural periods of buildings reduce with an increase in stiffness.

- Hard soil without MTMD is 7.93\% more displaced than fixed base without MTMD and soft soil without MTMD is $9.74 \%$ more displacement than fixed base without MTMD.

-There is a difference between the flexible base with and without MTMD. That is, hard soil without MTMD is $14.93 \%$ more displaced than hard soil with MTMD.

-And also there is a difference between the fixed base with and without MTMD. Fixed base without MTMD $36.1 \%$ more displaced than a fixed base with MTMD and soft soil with MTMD is 35.06\% more displacement than a fixed base with MTMD and hard soil with MTMD more displaced 30.92\% than fixed base with MTMD. - Fixed base structure with MTMD has high stiffness $(\mathrm{K})$ then it will also displace less (low U) and flexible base structure has low stiffness (K), it will displace much more (high $\mathrm{U}$ ) resulting in more or less the same amount of base shear $(\mathrm{K} \times \mathrm{U})$. Therefore, the building with more seismic weight will be having high base shear and low natural period.

- Overall, the analysis of this structure yielded better results under the conditions used by the multi-tuned mass damper. That means MTMD is effective in reducing lateral displacement of the structure can be used for structures under earthquake. 
- There is some difference between the fixed base with and without MTMD, the base shear of a fixed base with MTMD is $7.33 \%$ higher because it has higher stiffness and the story displacements are smaller than the fixed base without MTMD.

- And also there is a $5.7 \%$ difference between the flexible base with and without MTMD, base shear of a flexible base with MTMD has higher than flexible base without MTMD, but there is no wide difference between the two cases: fixed base and flexible base with MTMD because both are relatively they have high stiffness and low story displacement, but there is a small (1.022\%) difference between them, base shear of a fixed base with MTMD has a higher value.

Therefore, the building with more seismic weight will be having high base shear and low natural period.

\section{Acknowledgment}

The author would like to thank, without the passionate help of the author this paper couldn't pass all the up and downs with such ease. The authors would also like to express their gratitude to whosoever had contributed to their work either directly or indirectly.

\section{References}

1 Council on Tall Buildings and Urban Habitat/2010 Journal/Issue 4/David Da-Wei Lee; Martin Ng

2 Webster, A.C., and Vaicaitis, R. "Application of Tuned Mass Dampers To Control Vibrations of Composite Floor Systems" Engineering Journal, pp116-124, 2003.

3 C. Li, X. Xiong, and B. Cheng, "The optimum MTMD based on parameter combinations and acceleration transfer function," Journal of Vibration and Shock, vol. 20, no. 3, pp. 50-54, 2001.

4 BHRC, (2005). Seismic Design Code for Buildings Subjected to Earthquake. Building and Housing Research Center, Tehran, Iran.

5 Arefi, M.J. (2008). Effects of soil-structure interaction on the seismic response of existing R.C. frame buildings. A dissertation submitted in partial fulfillment of the requirements for the Master Degree in Earthquake Engineering and Engineering Seismology. Available online at: www. rose school.it/files/get/id/4458, accessed 28 April 2013

6 CSI, (2008). SAP2000: Static and Dynamic Finite Element Analysis of Structures, Advanced 12.0.0, Computers and Structures, Inc., Berkeley, California.

7 Tuned Mass Dampers for Buildings, Bridges, and Other Tall Structures/GERB Vibration Control Systems.

8 Nielson, A. H., (2009). Boundary Conditions for Seismic Analysis. The Society for Earthquake and Civil Engineering Dynamics, Newsletter, Vol. 21, No. 3, UK.

9 Wolf, J. P. (1985). Dynamic Soil-Structure Interaction, Prentice-Hall.

10 Wolf, J.P. (1994). Foundation Vibration Analysis Using Simple Physical Models. Prentice-Hall.

11 Jangid RS. Dynamic characteristics of structures with multiple tuned mass dampers. Structural Engineering and Mechanics 1995; 3:497-509. 